\title{
Adverse Drug Events and Hospital Pharmacy Practice: Thinking Outside Our Box
}

\author{
Peter J Zed
}

A

dverse drug events are unfavourable occurrences related to the use and misuse of medications. ${ }^{1}$ It has been estimated that adverse drug events account for more than 17 million emergency department visits and almost 9 million hospital admissions annually in the United States. ${ }^{2,3}$ A cost-of-illness model published in 2001 estimated that annual costs associated with morbidity and mortality secondary to adverse drug events exceeded US $\$ 177$ billion. ${ }^{3}$ Until recently, the effects of adverse drug events in Canada had not been characterized, but it is now evident that significant morbidity, mortality, and economic impact can be related to adverse drug events. More specifically, it has been estimated that as many as $25 \%$ of general medicine admissions and $12 \%$ of visits by adults to the emergency department in this country are directly related to adverse drug events, of which $70 \%$ are deemed preventable. ${ }^{4.5}$ In the Canadian Adverse Events Study, 7.5\% of all inpatients experienced an adverse event during their hospital stay and nearly $24 \%$ of the events were related to drug or fluid administration. ${ }^{6}$ Finally, in another study, $23 \%$ of patients experienced an adverse event within 30 days after hospital discharge, $72 \%$ of the events were associated with drugs, and $50 \%$ of the events were preventable. These staggering data suggest that we have underestimated the magnitude of this problem but also that we are presented with a tremendous opportunity to explore and implement strategies for both inpatients and outpatients to reduce these events. In this issue of the CJHP, we have 3 papers that once again remind us of the impact of adverse drug events and drug-related problems in hospital patients..$^{8-10}$

For over 20 years, pharmaceutical care has been the framework for our inpatient practice models. ${ }^{11}$ Prolonged and continuous access to the patient, to the patient's information, and to other health care providers places hospital pharmacists in a unique practice setting ideal for the identification, resolution, and prevention of drug-related problems. However, despite attempts to improve the communication of patient information at the time of discharge to the community setting, it is well established that this transition is not seamless. Shortcomings in communication, follow-up, and monitoring place patients at

risk in the immediate postdischarge period..$^{11,12}$ In the longer term, the system of dispersed health care providers in the community setting creates ongoing access and communication challenges. The community pharmacist's access to the patient's information and to other health care providers is also

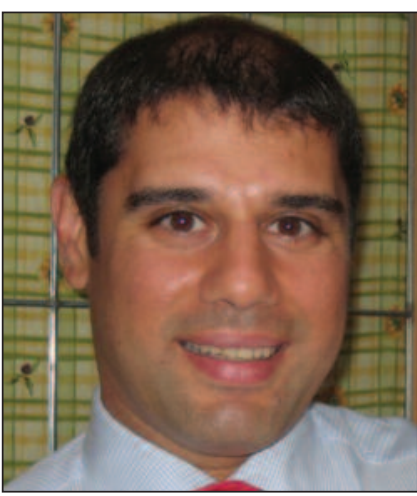
limited. Together, the complexities of these issues contribute to the high rates of adverse drug events that are seen both shortly after hospital discharge ${ }^{8}$ and in the longer-term, ambulatory care setting. ${ }^{13}$

Examples exist of programs and practice models that attempt to address these problems. However, there remains an opportunity for hospital pharmacists, working with other health care providers, to further enhance the care provided to patients after discharge from hospital. There is also an opportunity for hospital pharmacists and community pharmacists to start collaborating more closely to provide truly patient-centred pharmaceutical care. Although having less influence on care provided in the hospital setting, the changes in pharmacy legislation that are occurring throughout the country have enabled community pharmacists to expand their scope of practice and to provide more comprehensive pharmacy services. In addition, appropriate remuneration models are being developed in some provinces to support expanded pharmacy practice activities. Finally, enhanced use of technology will start to improve information access in all practice settings, facilitating better collaboration between heath care providers in both inpatient and outpatient care settings.

We must start to think outside our box of hospital practice, to explore innovative practice models, and to embrace approaches that expand the provision of our expertise to patients and other health care providers after the patient's discharge from 
hospital. The solutions are not simple, but the magnitude of the impact of adverse drug events on our patients deserves our attention. Closer collaboration with the community-based health care providers who care for our patients after they leave the hospital is a good place to begin. I am confident that with careful attention, reflection, and willingness to provide patientcentred care, an improved model of collaboration with community-based health care providers will have a significant effect in reducing adverse drug events.

\section{References}

1. Nebeker JR, Barach P, Samore MH. Clarifying adverse drug events: a clinician's guide to terminology, documentation, and reporting. Ann Intern Med 2004;140(10):795-801.

2. Bates DW, Spell N, Cullen DJ, Burdick E, Laird N, Petersen LA, et al.; Adverse Drug Events Prevention Study Group. The costs of adverse events in hospitalized patients. JAMA 1997;277(4):307-311.

3. Ernst FR, Grizzle AJ. Drug-related morbidity and mortality: updating the cost-of-illness model. J Am Pharm Assoc (Wash) 2001;41(2):192-199.

4. Samoy LJ, Zed PJ, Wilbur K, Balen RM, Abu-Laban RB, Roberts M. Drug-related hospitalizations in a tertiary care internal medicine service of a Canadian hospital: a prospective study. Pharmacotherapy 2006;26(11): 1578-1586.

5. Zed PJ, Abu-Laban RB, Balen RM, Loewen PS, Hohl CM, Brubacher JR, et al. Incidence, severity and preventability of medication-related visits to the emergency department: a prospective study. CMAJ 2008;178(12): 1563-1569.

6. Baker GR, Norton PG, Flintoft V, Blais R, Brown A, Cox J, et al. The Canadian Adverse Events Study: the incidence of adverse events among hospital patients in Canada. CMAJ 2004;170(11):1678-1686.

7. Forster AJ, Clark HD, Menard A, Dupuis N, Chernish R, Chandok N, et al. Adverse events among medical patients after discharge from hospital. CMAJ 2004;170(3):345-349. Erratum in: CMAJ 2004;170(5):771.
8. Cashin RP, Yang M. Medications prescribed and occurrence of falls in general medicine inpatients. Can J Hosp Pharm 2011;64(5):321-326.

9. Kanji Z, Su VCH, Mainra R. Nitrofurantoin-induced pulmonary reaction involving respiratory symptoms: case report. Can J Hosp Pharm 2011;64(5):362-365.

10. Mabasa VH, Malyuk DL, Weatherby EM, Chan A. A standardized, structured approach to identifying drug-related problems in the intensive care unit: FASTHUG-MAIDENS. Can J Hosp Pharm 2011;64(5): 366-369.

11. van Walraven C, Taljaard M, Bell CM, Etchells E, Zarnke KB, Stiell IG, et al. Information exchange among physicians caring for the same patent in the community. CMAJ 2008;179(10):1013-1018.

12. Hepler CD, Strand LM. Opportunities and responsibilities in pharmaceutical care. Am J Hosp Pharm 1990;47(3):533-543.

13. Taché SV, Sönnichsen A, Ashcroft DM. Prevalence of adverse drug events in ambulatory care: a systematic review. Ann Pharmacother 2011;45(7-8): 977-989.

Peter J Zed, BSC, BSC(Pharm), ACPR, PharmD, FCSHP, is Clinical Coordinator, Department of Pharmacy, and Pharmacotherapeutic Specialist Emergency Medicine, Queen Elizabeth II Health Sciences Centre, and Associate Professor, College of Pharmacy and Department of Emergency Medicine, Dalhousie University, Halifax, Nova Scotia. He is also an Associate Editor with the CJHP.

\section{Address correspondence to:}

Dr Peter J Zed

Department of Pharmacy - Halifax Infirmary

Queen Elizabeth II Health Sciences Centre

1796 Summer Street

Halifax NS B3H 3 A7

e-mail: peter.zed@dal.ca

\section{ON THE FRONT COVER}

\section{Coquihalla Highway, British Columbia}

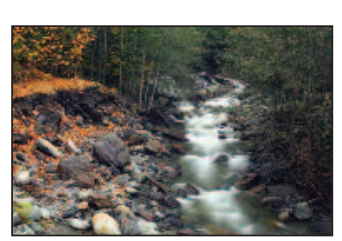

This image was taken in October 2009 just off the Coquihalla Highway, east of Hope, British Columbia. The photographer, Ken Wou, had just attended a photography workshop in Vancouver and was returning home to Kamloops, hoping to find a location to apply his new-found knowledge. Using a Canon 50D camera and Canon
EF 24-105 mm f/4 L IS USM lens on a Gitzo tripod, Ken took this image at $28 \mathrm{~mm}$, ISO 100, f/18, with an 8-second exposure. The silky smooth waters were nicely balanced with the changing colours on this late evening of an autumn day.

The CJHP would be pleased to consider photographs featuring Canadian scenery taken by CSHP members for use on the front cover of the journal. If you would like to submit a photograph, please send an electronic copy (minimum resolution $300 \mathrm{dpi}$ ) to Colleen Drake at cdrake@cshp.ca. 